\title{
Carrier screening panels for Ashkenazi Jews: Is more better?
}

\author{
Jennifer R. Leib, $M S^{1,2}$, Sarah E. Gollust, BA ${ }^{3,4}$, Sara Chandros Hull, $P h D^{3,4}$, and Benjamin S. Wilfond, $M D^{3,4}$
}

\begin{abstract}
Purpose: To describe the characteristics of Ashkenazi Jewish carrier testing panels offered by US Laboratories, including what diseases are included, the labels used to describe the panels, and the prices of individual tests compared to the prices of panels for each laboratory. Methods: GeneTests (http://www.genetests.org) was searched for laboratories that offered Tay-Sachs disease testing. Information was obtained from laboratory web sites, printed brochures, and telephone calls about tests/panels. Results: Twenty-seven laboratories offered up to 10 tests. The tests included two diseases associated with death in childhood (Niemann-Pick type A and Tay-Sachs disease), five with moderate disability and a variably shortened life span (Bloom syndrome, Canavan disease, cystic fibrosis, familial dysautonomia, Fanconi anemia, and mucolipidosis type IV), and two diseases that are not necessarily disabling or routinely shorten the lifespan (Gaucher disease type I and DFNB1 sensorineural hearing loss). Twenty laboratories offered a total of 27 panels of tests for three to nine diseases, ranging in price from $\$ 200$ to $\$ 2082$. Of these, 15 panels cost less than tests ordered individually. The panels were described by 24 different labels; eight included the phrase Ashkenazi Jewish Disease or disorder and six included the phrase Ashkenazi Jewish Carrier. Conclusion: There is considerable variability in the diseases, prices, and labels of panels. Policy guidance for establishing appropriate criteria for inclusion in panels may be useful to the Ashkenazi Jewish community, clinicians, and payers. Pricing strategies that offer financial incentives for the use of "more tests" should be reexamined. Genet Med 2005:7(3):185-190.
\end{abstract}

Key Words: carrier screening, Ashkenazi Jews, guidelines, policy development, stigmatization

The Ashkenazi Jewish community has been increasingly involved in genetic research, in part because this community has been characterized as interested in and willing to participate in genetics research ${ }^{1}$ and because the founder effect and genetic drift contribute to making the population desirable for research. ${ }^{2,3}$ The Jewish community has historically been involved with screening programs beginning with carrier screening for Tay-Sachs disease in the 1970s. ${ }^{4,5}$ An example of such community involvement is the Dor Yeshorim screening program, developed specifically for populations of Orthodox Jews in the New York City area, to screen community members for Tay-

\footnotetext{
From the ${ }^{I}$ Neurogenetics Branch, National Institute of Neurological Diseases and Stroke, National Institutes of Health; ${ }^{2}$ Policy and Program Analysis Branch, National Human Genome Research Institute, National Institutes of Health; ${ }^{3}$ Social and Behavioral Research Branch, National Human Genome Research Institute, National Institutes of Health; and the ${ }^{4}$ Department of Clinical Bioethics, Warren G Magnuson Clinical Center, National Institutes of Health, Bethesda, Maryland.

Benjamin Wilfond, MD, Building 10 Room 1C 118 MSC 1156, 9000 Rockville Pike, Bethesda, MD 20892-1156.

The opinions expressed in this article are those of the authors and do not reflect the opinions or policies of the National Human Genome Research Institute, the National Institute of Neurological Disorders and Stroke, the National Institutes of Health, or the Department of Health and Human Services.

Received: October 26, 2004.

Accepted: December 10, 2004.
}

DOI: 10.1097/01.GIM.0000156527.87525.8F
Sachs disease while respecting standards of confidentiality and Jewish traditions. ${ }^{6}$ Moving beyond this paradigm of community-directed screening, molecular genetic laboratories are now beginning to offer panels of multiple molecular genetic tests designated as "Ashkenazi Jewish" carrier tests. ${ }^{7}$

Media coverage of research and screening programs as well as scientific and lay texts have identified certain diseases with labels such as "Ashkenazi Jewish Diseases" and "Jewish Genetic Disorders.", 9 These labels have triggered concerns about stigma within the Ashkenazi community. ${ }^{10,11}$ Journalists, misinterpreting some research findings, have inappropriately communicated the idea that Jewish people carry more mutations than other groups. ${ }^{1}$ Advertisements marketing predictive tests toward the Ashkenazi Jewish community may exacerbate these misunderstandings. ${ }^{12}$

Some policy issues related to the use of panels for carrier tests targeted toward the Ashkenazi Jewish community have been raised, $, 713,14$ including concerns about informed decision making in the reproductive context and the extent that testing for specific conditions is welcomed by the community. This study is the first systematic description of the composition and availability of such panels through molecular genetic laboratories. Our objectives were to describe the diseases, including carrier frequency and clinical features, and to describe the panels offered, including the diseases, prices, and panel labels. 
These data can be useful in making policy decisions about design and development of screening panels.

\section{METHODS}

The availability of Tay-Sachs disease carrier screening was used as a proxy to identify laboratories that might provide carrier testing for the disorders more common in individuals of Ashkenazi Jewish heritage. A search performed on December 19, 2002 through GeneTests (http://www.genetests.org) identified 31 laboratories that offered testing for Tay-Sachs in the United States. One additional program not listed on GeneTests was identified at the American Society of Human Genetics meeting in October 2002. These laboratories were contacted between December 23, 2002 and February 28, 2003 to verify that Tay-Sachs testing was still offered. Five laboratories no longer offered Tay-Sachs disease testing. Thus, 27 laboratories were evaluated, which included a few programs that send out samples to secondary laboratories, to determine the characteristics of any Ashkenazi Jewish disease panels that were offered.

A panel was considered to be any set of genetic tests that were offered together with Tay-Sachs disease testing. Information was collected through brochures distributed at professional society meetings and a review of each individual laboratory's web site. For some laboratories, a follow-up telephone call was made for additional information or clarification. For each laboratory, information was collected about the tests offered, panels offered, names of panel labels, and pricing information. Clinical information about each disease was obtained from the Online Mendelian Inheritance in Man (OMIM) database. ${ }^{15}$ The carrier frequencies cited by these sources are compilations from primary data sources. The NIH Office of Human Subjects Research exempted this study from IRB review because the information was publicly available.

\section{RESULTS}

The laboratories offered testing for as many as 10 different autosomal recessive diseases. Table 1 shows that these diseases vary widely in the heterozygote frequency, clinical features, and life expectancy. The heterozygote frequency for Ashkenazi Jewish individuals ranged from approximately $1 / 13$ to $1 / 127$. The relative carrier frequency was higher in Ashkenazi Jews for all diseases except for cystic fibrosis and DFNB1 sensorineural hearing loss. For all diseases, there were specific mutations associated with Ashkenazi Jews (founder effect). Five of the diseases result in progressive neurodegeneration (Canavan disease, familial dysautonomia, mucolipidosis type IV, NiemannPick type A, and Tay-Sachs disease), two predispose to malignancy (Bloom syndrome and Fanconi anemia), two reduce fertility (Bloom syndrome and cystic fibrosis), and two manifest with dysmorphic features (Bloom syndrome and mucolipidosis type IV). The tests included two diseases associated with death in childhood (Niemann-Pick type A and Tay-Sachs disease), five with moderate disability and a variably shortened life span (Bloom syndrome, Canavan disease, cystic fibrosis, familial dysautonomia, Fanconi anemia, and mucolipidosis type IV), and two that are not necessarily disabling or routinely

Table 1

Diseases included in Ashkenazi Jewish carrier testing

\begin{tabular}{|c|c|c|c|}
\hline Disease & $\begin{array}{l}\text { Carrier frequency in } \\
\text { Ashkenazi Jews }\end{array}$ & Clinical features & Life expectancy \\
\hline Bloom Syndrome (BS) & $1 / 110$ & $\begin{array}{l}\text { Dysmorphic features } \\
\text { Reduced fertility } \\
\text { Predisposition to malignancy (leukemia) }\end{array}$ & Childhood to young adulthood \\
\hline Canavan disease $(\mathrm{CD})$ & $1 / 59$ & Progressive neurodegeneration & Childhood to young adulthood \\
\hline Cystic fibrosis (CF) & $1 / 33$ & $\begin{array}{l}\text { Reduced fertility } \\
\text { Pulmonary disease } \\
\text { Pancreatic insufficiency }\end{array}$ & Childhood to young adulthood \\
\hline Familial dysautonomia (FD) & $1 / 32$ & $\begin{array}{l}\text { Progressive neurodegeneration } \\
\text { Autonomic dysfunction }\end{array}$ & Childhood to young adulthood \\
\hline Fanconi anemia (FA) & $1 / 89$ & $\begin{array}{l}\text { Dysmorphic features } \\
\text { Pancytopenia } \\
\text { Predisposition to malignancy (leukemia) }\end{array}$ & Childhood to young adulthood \\
\hline Gaucher disease type 1 (GD) & $1 / 13$ & Thrombocytopenia, anemia and bone lesions & Normal \\
\hline Hearing loss (DFNB1) & $1 / 21$ & Hearing loss & Normal \\
\hline Mucolipidosis type IV (MLP) & $1 / 127^{27}$ & $\begin{array}{l}\text { Dysmorphic features } \\
\text { Progressive neurodegeneration }\end{array}$ & Childhood to young adulthood \\
\hline Niemann-Pick type A (NP) & $1 / 90^{28}$ & Progressive neurodegeneration & Early childhood \\
\hline Tay-Sachs disease (TS) & $1 / 31$ & Progressive neurodegeneration & Early childhood \\
\hline
\end{tabular}

All data from Online Mendelian Inheritance in Man, except when noted. 
shorten the lifespan (Gaucher disease type I and DFNB1 sensorineural hearing loss).

Of the 27 laboratories offering testing for these diseases, 20 offered panels encompassing three to nine diseases, four of which offered multiple panels (Table 2). The median number of tests in the panels was six. The most common panel included Tay-Sachs disease, cystic fibrosis, and Canavan disease. This three-test panel was offered by six laboratories, and the price ranged from $\$ 200$ to $\$ 375$. The most expensive panel included tests for eight diseases and cost $\$ 2082$. Another laboratory offered a panel with tests for nine diseases for $\$ 1310$. In contrast, a third laboratory also provided a panel with tests for nine diseases and charged $\$ 450$. The most economical panel included tests for seven diseases and cost $\$ 250$. The least expensive panel included tests for three diseases and cost \$200. Of 27 panels, 15 cost less, four did not differ, seven were unknown, and one cost more than if the tests were ordered individually. Each of the 15 panels that cost less than the individual tests was offered by one of 11 of the 20 laboratories.

The laboratories used 24 different labels to describe the panels available for Ashkenazi Jewish carrier screening (Table 3). All include the terms Ashkenazi or Jewish or both. Eight included the phrase Ashkenazi Jewish disease or disorder, and six included the phrase Ashkenazi Jewish carrier. Others referenced the diseases as being associated with Ashkenazi Jewish people with titles such as Jewish Heritage Panel, Jewish Inheritance Disease Screening, Ashkenazi Jewish Genetic Screening, Jewish DNA Panel, and Jewish Ancestry Reproductive Panel.

\section{DISCUSSION}

This study shows significant variability in the panels, including the number of diseases, the characteristics of the diseases, prices, and labels. This raises normative questions about which diseases should be included, whether it is appropriate to provide financial incentives that would encourage testing for more conditions, and how the panels should be labeled.

Each of the 10 conditions is described as "Ashkenazi Jewish diseases," yet they differ in characteristics such as carrier frequency and phenotype, and even whether there is an increased carrier frequency in the Ashkenazi community. What factors determine what is a Jewish genetic disease and justify inclusion in a carrier-testing panel?

Carrier frequency among Ashkenazi Jews could be the basis for panel inclusion. However, the range of carrier frequency spans from approximately $1 / 13$ for Gaucher disease to $1 / 127$ for mucolipidosis type IV. Other diseases with comparable carrier frequencies are not included. For example, carrier testing for spinal muscular atrophy (SMA) is not typically offered in the absence of an affected family member. The carrier frequency for SMA, an autosomal recessive motor neuron disease that in its most severe form is lethal in infancy, is $1 / 50 .{ }^{16}$ Conversely, carrier testing for some conditions in these panels is not routinely offered to other populations that have similar diseases frequencies, as is the case with DFNB1 sensorineural hearing loss.
Disease severity might justify the inclusion of a disease in a panel. Two of the diseases included in the panels cause death in early childhood. However, two other conditions have mild phenotypes; DFNB1 sensorineural hearing loss and Gaucher disease (which can be ameliorated with enzyme replacement therapy). In these cases, severity judgments are complex and value-based, and particularly challenging to use to make reproductive decisions.

These 10 diseases have no single feature in common except the presence of a founder mutation. Testing for five or fewer mutations for each of these diseases offers sensitivities well over $90 \%$, allowing for the development of simple, inexpensive testing relative to tests that require sequencing entire genes. If the presence of a founder mutation is sufficient to justify a test's inclusion on a panel, then Ashkenazi Jewish panels should include testing for autosomal dominant conditions such as Usher syndrome, ${ }^{17}$ breast and colon cancer, ${ }^{18}$ and torsion dystonia (DYT1). ${ }^{7}$ However, the inclusion of such conditions raises additional ethical concerns related to presymptomatic testing, including the complexities of incomplete penetrance and the availability of interventions.

The rationale for carrier testing is strong: to identify carrier couples and provide them with the opportunity to pursue reproductive options if desired and potentially, to reduce the incidence of disease. ${ }^{19}$ Disease selection for carrier testing is a complex policy decision that is in part related to carrier frequency, severity, and feasibility of testing within a population. However, it is also important to minimize the likelihood that population screening programs will have adverse effects on the population.

Even for Tay-Sachs disease, where carrier screening has been traditionally supported by the Jewish community and has clear benefits, some commentators have raised questions about the potential for stigmatization within the community because of the language used in promotional materials. ${ }^{20}$ The choice of words that laboratories used to describe the panels raises similar concerns. The panels' names suggest that these diseases are exclusive to the Ashkenazi Jewish population. Furthermore, offering panels with increasing numbers of conditions may imply that Jewish people are at risk for diseases more than other ethnic groups. These impressions may be filtering into the professional realm: we have heard anecdotal evidence of a colloquial phrase, the Jewish Cocktail, used by some genetics professionals use to describe these testing panels.

The term cocktail is also suggestive of an elixir that provides reassurance. However, increasing the number of tests will result in fewer people obtaining reassuring results. In a recent study of screening 2427 Ashkenazi Jews with an panel for eight conditions, one in seven were carriers for at least one condition. $^{21}$ Offering financial incentives for individuals to have tests for more conditions will only exacerbate this concern. More importantly, the financial incentives require that individuals be willing to pay more if they do not want to have a particular test done. For example, Laboratory \#8 offered a panel of seven diseases for $\$ 450$, but if a patient wanted to exclude Gaucher disease, the cost for the other six conditions 
Table 2

Laboratory prices for individual tests and Ashkenazi Jewish disease panels

\begin{tabular}{|c|c|c|c|c|c|c|c|c|c|c|c|c|}
\hline Lab & TS & $\mathrm{CF}$ & $\mathrm{CD}$ & GD & NP & FA & BS & MLP & FD & DFNB1 & Panel price & $\begin{array}{c}\text { Price if tests } \\
\text { ordered separately }\end{array}$ \\
\hline \multirow[t]{2}{*}{1} & $\$ 130$ & $\$ 265$ & $\$ 230$ & $\$ 150$ & $\$ 230$ & $\$ 170$ & $\$ 170$ & $\$ 230$ & $\$ 215$ & & & \\
\hline & $\sqrt{ }$ & $\checkmark$ & $\sqrt{ }$ & $\sqrt{ }$ & $\sqrt{ }$ & $\checkmark$ & $\checkmark$ & $\checkmark$ & $\checkmark$ & & $\$ 1315$ & $(\$ 1790)$ \\
\hline \multirow[t]{2}{*}{2} & $\$ 50$ & $\$ 50$ & $\$ 50$ & $\$ 50$ & $\$ 50$ & $\$ 50$ & $\$ 50$ & & $\$ 50$ & $\$ 50$ & & \\
\hline & $\checkmark$ & $\checkmark$ & $\checkmark$ & $\checkmark$ & $\checkmark$ & $\checkmark$ & $\checkmark$ & & $\checkmark$ & $\checkmark$ & $\$ 450$ & $(\$ 450)$ \\
\hline \multirow[t]{3}{*}{3} & $\$ 242$ & $\$ 268$ & $\$ 345$ & $\$ 360$ & $\$ 182$ & $\$ 205$ & $\$ 235$ & & $\$ 220$ & & & \\
\hline & $\checkmark$ & $\checkmark$ & $\sqrt{ }$ & $\checkmark$ & $\checkmark$ & $\checkmark$ & $\checkmark$ & & $\checkmark$ & & $\$ 2082$ & $(\$ 2057)$ \\
\hline & $\checkmark$ & $\sqrt{ }$ & $\sqrt{ }$ & $\sqrt{ }$ & $\sqrt{ }$ & $\sqrt{ }$ & & & & & $\$ 495$ & $(\$ 1602)$ \\
\hline \multirow[t]{2}{*}{4} & $\$ 110$ & $\$ 195$ & $\$ 195$ & $\$ 125$ & $\$ 110$ & $\$ 110$ & $\$ 110$ & & $\$ 110$ & $\$ 250$ & & \\
\hline & $\sqrt{ }$ & $\sqrt{ }$ & $\checkmark$ & $\sqrt{ }$ & $\sqrt{ }$ & $\checkmark$ & $\sqrt{ }$ & & $\sqrt{ }$ & & $\$ 595$ & $(\$ 1065)$ \\
\hline \multirow[t]{2}{*}{5} & $\$ 139$ & $\$ 332$ & $\$ 123$ & $\$ 200$ & $\$ 166$ & $\$ 76$ & $\$ 76$ & $\$ 91$ & $\$ 106$ & & & \\
\hline & $\sqrt{ }$ & & $\checkmark$ & $\checkmark$ & $\sqrt{ }$ & & $\sqrt{ }$ & $\checkmark$ & $\sqrt{ }$ & & $\$ 1310$ & $(\$ 1310)$ \\
\hline \multirow[t]{2}{*}{6} & $\$ 120$ & $\$ 240$ & $\$ 120$ & $\$ 120$ & & $\$ 120$ & $\$ 120$ & & $\$ 120$ & & & \\
\hline & $\checkmark$ & $\sqrt{ }$ & $\checkmark$ & $\sqrt{ }$ & & $\checkmark$ & $\checkmark$ & & $\checkmark$ & & $\$ 960$ & $(\$ 960)$ \\
\hline \multirow[t]{2}{*}{7} & $\$ 100$ & $\$ 150$ & $\$ 100$ & $\$ 100$ & $\$ 150$ & $\$ 100$ & $\$ 100$ & & $\$ 100$ & & & \\
\hline & $\checkmark$ & $\checkmark$ & $\checkmark$ & $\checkmark$ & $\checkmark$ & $\checkmark$ & $\checkmark$ & & & & $\$ 900$ & $(\$ 900)$ \\
\hline \multirow[t]{2}{*}{8} & $\$ 160$ & $\$ 270$ & $\$ 210$ & $\$ 210$ & $\$ 210$ & $\$ 210$ & $\$ 210$ & & & & & \\
\hline & $\sqrt{ }$ & $\checkmark$ & $\checkmark$ & $\checkmark$ & $\checkmark$ & $\sqrt{ }$ & $\checkmark$ & & & & $\$ 450$ & $(\$ 1480)$ \\
\hline \multirow[t]{3}{*}{9} & $\$ 75$ & $\$ 100$ & $\$ 100$ & $\$ 100$ & $\$ 100$ & $\$ 60$ & $\$ 60$ & & & & & \\
\hline & $\checkmark$ & $\sqrt{ }$ & $\checkmark$ & $\sqrt{ }$ & $\checkmark$ & $\checkmark$ & $\checkmark$ & & & & $\$ 400$ & $(\$ 595)$ \\
\hline & $\checkmark$ & & $\sqrt{ }$ & $\sqrt{ }$ & $\checkmark$ & $\checkmark$ & $\sqrt{ }$ & & & & $\$ 350$ & $(\$ 495)$ \\
\hline \multirow[t]{2}{*}{10} & $\$ 45$ & $\$ 75$ & $\$ 30$ & $\$ 60$ & & $\$ 15$ & $\$ 15$ & & $\$ 15$ & & & \\
\hline & $\checkmark$ & $\checkmark$ & $\checkmark$ & $\checkmark$ & & $\sqrt{ }$ & $\checkmark$ & & $\checkmark$ & & $\$ 250$ & $(\$ 255)$ \\
\hline \multirow[t]{6}{*}{11} & $\$ 275$ & $\$ 150$ & $\$ 275$ & $\$ 275$ & NAI & NAI & & & & & & \\
\hline & $\checkmark$ & $\sqrt{ }$ & $\checkmark$ & $\sqrt{ }$ & $\sqrt{ }$ & $\checkmark$ & & & & & $\$ 425$ & $(\$ 700+)$ \\
\hline & $\sqrt{ }$ & $\checkmark$ & $\sqrt{ }$ & & $\sqrt{ }$ & $\checkmark$ & & & & & $\$ 425$ & $(\$ 700+)$ \\
\hline & & & & & & $\sqrt{ }$ & $\sqrt{ }$ & & & & $\$ 250$ & (NA) \\
\hline & & & & & $\checkmark$ & $\checkmark$ & $\checkmark$ & & & & $\$ 250$ & $(\$ 275+)$ \\
\hline & $\checkmark$ & $\sqrt{ }$ & $\checkmark$ & & & & & & & & $\$ 250$ & $(\$ 700)$ \\
\hline \multirow[t]{2}{*}{12} & $\$ 300$ & $\$ 150$ & $\$ 150$ & $\$ 150$ & & & & & $\$ 150$ & & & \\
\hline & $\checkmark$ & $\checkmark$ & $\checkmark$ & $\checkmark$ & & & & & $\checkmark$ & & $\$ 650$ & $(\$ 900)$ \\
\hline \multirow[t]{3}{*}{13} & NAI & NAI & NAI & NAI & & & & & & & & \\
\hline & $\checkmark$ & $\sqrt{ }$ & $\checkmark$ & $\checkmark$ & & & & & & & $\$ 720$ & (NA) \\
\hline & & $\checkmark$ & $\checkmark$ & $\checkmark$ & & & & & & & $\$ 480$ & $(\mathrm{NA})$ \\
\hline \multirow[t]{2}{*}{14} & $\$ 100$ & $\$ 170$ & NAI & & & & & & & & & \\
\hline & $\checkmark$ & $\sqrt{ }$ & $\sqrt{ }$ & & & & & & & & $\$ 375$ & (NA) \\
\hline
\end{tabular}


Table 2

Continued

\begin{tabular}{|c|c|c|c|c|c|c|c|c|c|c|c|c|}
\hline Lab & TS & CF & $\mathrm{CD}$ & GD & NP & FA & BS & MLP & FD & DFNB1 & Panel price & $\begin{array}{c}\text { Price if tests } \\
\text { ordered separately }\end{array}$ \\
\hline \multirow[t]{2}{*}{15} & $\$ 210$ & $\$ 170$ & $\$ 210$ & & & & & & & & & \\
\hline & $\sqrt{ }$ & $\checkmark$ & $\sqrt{ }$ & & & & & & & & $\$ 350$ & $(\$ 590)$ \\
\hline \multirow[t]{2}{*}{16} & NAI & NAI & NAI & & & & & & & & & \\
\hline & $\sqrt{ }$ & $\sqrt{ }$ & $\sqrt{ }$ & & & & & & & & $\$ 300$ & (NA) \\
\hline \multirow[t]{2}{*}{17} & NAI & NAI & NAI & $\$ 230$ & $\$ 230$ & & $\$ 230$ & & $\$ 230$ & $\$ 430$ & & \\
\hline & $\sqrt{ }$ & $\sqrt{ }$ & $\sqrt{ }$ & & & & & & & & $\$ 285$ & (NA) \\
\hline \multirow[t]{2}{*}{18} & $\$ 200$ & $\$ 250$ & $\$ 200$ & & $\$ 200$ & & & & & & & \\
\hline & $\checkmark$ & & $\sqrt{ }$ & & & $\checkmark$ & & & & & $\$ 250$ & $(\$ 600)$ \\
\hline \multirow[t]{2}{*}{19} & $\$ 334$ & $\$ 325$ & $\$ 314$ & $\$ 388$ & $\$ 247$ & $\$ 179$ & $\$ 280$ & & $\$ 280$ & $\$ 280$ & & \\
\hline & $\checkmark$ & $\checkmark$ & $\sqrt{ }$ & & & & & & & & $\$ 200$ & $(\$ 973)$ \\
\hline \multirow[t]{2}{*}{20} & $\$ 265$ & NAI & NAI & NAI & $\$ 265$ & & & & & & & \\
\hline & & $\checkmark$ & $\checkmark$ & $\checkmark$ & & & & & & & $\$ 200$ & (NA) \\
\hline
\end{tabular}

For each laboratory, the upper line is the price for each test. Each lower line with the "checks" indicates which tests are in the panels. Some laboratories have more than one panel.

NAI, not available individually; NA, not available.

Table 3

Panels labels

Ashkenazi Genetic Screen

Ashkenazi Jewish Carrier Panel

Ashkenazi Jewish Carrier Screen

Ashkenazi Jewish Carrier Screening

Ashkenazi Jewish Carrier Test

Ashkenazi Jewish Carrier Testing

Ashkenazi Jewish Disease Screen

Ashkenazi Jewish Genetic Disease Panel

Ashkenazi Jewish Genetic Disease Screening Program

Ashkenazi Jewish Genetic Screening

Ashkenazi Jewish Panel

Ashkenazi Disease Plus

Ashkenazi Disease Screen

Carrier Testing for Ashkenazi Jewish (Eastern European) Families

Full Ashkenazi Panel

Jewish Ancestry Reproductive Panel

Jewish DNA Panel

Jewish Genetic Disease Panel

Jewish Genetic Diseases

Jewish Genetic Screen I and II

Jewish Genetic Update 1 and 2

Jewish Heritage Panel

Jewish Inheritance Disease Screening

Tay-Sachs and Jewish Disorders would be $\$ 1370$. This may be an undue inducement and make informed decision making (if a patient does not value knowledge of carrier status for a particular disease and its implications for reproductive decision-making) more difficult. This approach deserves careful reexamination. It may not be an ethically sound policy in the reproductive context to have financial penalties when a person decides to not have additional tests for a range of conditions.

The approach to deciding which diseases to include in carrier screening panels should be the result of a deliberative process based on empirical evidence of benefits and harms and a normative assessment of value, rather than being driven by laboratories' testing menus. ${ }^{22}$ Screening guidelines should develop criteria related to carrier frequency, severity, and test sensitivity. ${ }^{23}$ The application of these criteria should arise out of a consensus of genetics professionals, laboratory directors, and members of the Ashkenazi Jewish community. Importantly, the community can provide insight into appropriate labels, which could minimize the potential for stigma and inaccurate assumptions. Guidelines would promote consistency in what tests are offered to patients and in the development of culturally sensitive education materials.

There are several limitations to this study. First, prices and panels described in this study reflect a specific time period in 2003. Because laboratories update their menus and price lists, these may not be current at the time of publication. Additionally, further research is needed to assess the utilization of such panels by the Ashkenazi population, the validity of concerns about stigmatization, and the rationale laboratories use for developing panels and establishing pricing.

The development of guidelines does not ensure that there will be no problems. Despite the significant discussion and 
planning for the cystic fibrosis population screening guidelines, ${ }^{24,25}$ there have been still problems with misinterpretation of test results that resulted in unnecessary use of prenatal diagnosis procedures. ${ }^{26}$ Ashkenazi Jewish carrier testing includes tests for diseases of variable carrier frequency and severity. Undoubtedly, this type of carrier testing is more complicated than offering a single cystic fibrosis test. Nevertheless, it is important to develop a rational approach to determine which tests to offer because this experience will set the stage as laboratories consider making genetic testing panels more available to the general population, not only for carrier testing but for other markers of disease risk.

\section{ACKNOWLEDGMENTS}

We wish to thank the following individuals who provided us with comments on earlier versions of this manuscript: Cindy Dolan, Ezekiel Emanuel, Colleen McBride, Robert Nussbaum, and Roberta Pagon.

\section{References}

1. Rothenberg KH, Rutkin AB. Toward a framework of mutualism: the Jewish community in genetics research. Community Genet 1998;1:148-153.

2. Risch N, Tang H, Katzenstein H, Ekstein J. Geographic distribution of disease mutations in the Ashkenazi Jewish population supports genetic drift over selection. Am J Hum Genet 2003;72:812-822.

3. Zlotogora J, Bach G, Munnich A. Molecular basis of mendelian disorders among Jews. Mol Genet Metab 2000;69:169-180.

4. Kaplan F. Tay-Sachs disease carrier screening: a model for prevention of genetic disease. Genet Test 1998;2:271-292.

5. Kaback M, Lim-Steele J, Dabholkar D, Brown D, Levy N, Zeiger K. Tay-Sachs disease-carrier screening, prenatal diagnosis, and the molecular era. An international perspective, 1970 to 1993. The International TSD Data Collection Network. JAMA 1993;270:2307-2315.

6. Levin M. Screening Jews and genes: a consideration of the ethics of genetic screening within the Jewish community: challenges and responses. Genet Test 1999;3:207-213.

7. Gilbert F. Establishing criteria for a carrier detection panel: lessons from the Ashkenazi Jewish model. Genet Test 1998;2:301-304.

8. Goodman RM. Genetic Disorders Among the Jewish People. Baltimore: The Johns Hopkins University Press; 1979.
9. Abel EL. Jewish Genetic Disorders: A Layman's Guide. Jefferson, North Carolina: McFarland and Company, Inc; 2001.

10. Lehrman S. Jewish leaders seek genetic guidelines. Nature 1997;389:322.

11. Wadman M. Jewish leaders meet NIH chiefs on genetic stigmatization fears. Nature 1998;392:851.

12. Gollust SE, Hull SC, Wilfond BS. Limitations of direct-to-consumer advertising for clinical genetic testing. JAMA 2002;288:1762-1767.

13. Zinberg RE, Kornreich R, Edelmann L, Desnick RJ. Prenatal genetic screening in the Ashkenazi Jewish population. Clin Perinatol 2001;28:367-382.

14. Eng CM, Desnick RJ. Experiences in molecular-based prenatal screening for Ashkenazi Jewish genetic diseases. Adv Genet 2001;44:275-296.

15. Online Mendelian Inheritance in Man [Internet]. 2003. Available at: http://www.ncbi.nlm.nih.gov/Omim/

16. Ogino S, Wilson RB. Genetic testing and risk assessment for spinal muscular atrophy (SMA). Hum Genet 2002;111:477-500.

17. Ben-Yosef T, Ness SL, Madeo AC, et al. A mutation of PCDH15 among Ashkenazi Jews with the type 1 Usher syndrome. N Engl J Med 2003;348:1664-1670.

18. Ostrer H. A genetic profile of contemporary Jewish populations. Nat Rev Genet 2001;2:891-898.

19. Andrews LB, Fullarton JE, Holtzman NA, Motulsky AG. Assessing Genetic Risks. Washington, D.C. National Academy Press; 1994.

20. Goodman MJ, Goodman LE. The overselling of genetic anxiety. Hastings Cent Rep 1982;12:20-27.

21. Strom CM, Crossley B, Redman JB et al. Molecular screening for diseases frequent in Ashkenazi Jews: lessons learned from more than 100,000 tests performed in a commercial laboratory. Genet Med 2004;6:145-152.

22. Wilfond BS, Nolan K. National policy development for the clinical application of genetic diagnostic technologies. Lessons from cystic fibrosis. JAMA 1993;270:2948 2954.

23. Holtzman NA, Watson MS. Promoting Safe and Effective Genetic Testing in the United States Final Report of the Task Force on Genetic Testing; 1997. Bethesa, MD.

24. Grody WW, Cutting GR, Klinger KW, Richards CS, Watson MS, Desnick RJ. Laboratory standards and guidelines for population-based cystic fibrosis carrier screening. Genet Med 2001;3:149-154.

25. Ob-Gyns Offering Large-Scale Cystic Fibrosis ScreeningRepresents First Major Clinical Change from the Human Genome Project. American College of Obstetricians and Gynecologists. Available at: http://www.acog.org/from_home/publications/press_releases/nr12-12-01-2.cfm. Accessed May 16, 2003.

26. Vastag B. Cystic fibrosis gene testing a challenge: experts say widespread use is creating unnecessary risks. JAMA 2003;289:2923-2924.

27. Edelmann L, Dong J, Desnick RJ, Kornreich R. Carrier screening for mucolipidosi type IV in the American Ashkenazi Jewish population. Am J Hum Genet 2002;70: 1023-1027.

28. Patterson M. Niemann-Pick Disease, Type C. GeneReviews [Internet database]. September 10, 2001. Available at: http://www.genetests.org. Accessed April 2003. 